\title{
GOVERNANÇA METROPOLITANA NA AMÉRICA LATINA Breve análise sobre o modelo de gestão em oito países da região
}

\section{METROPOLITAN GOVERNANCE IN LATIN AMERICA $A$ brief analysis of public administration model in eight countries of the region}

\author{
A. Cid Blanco Junior \\ Faculdade de Arquitectura; Universidade de Lisboa, Portugal \\ cidblanco@uol.com.br \\ B. Bárbara Oliveira Marguti \\ Instituto de Pesquisas Econômicas Avançadas; Brasília, Brasil \\ barbara.marguti@ipea.gov.br
}

\section{RESUMO}

Esse artigo visa compreender, comparativamente, os principais aspectos da governança metropolitana na América Latina, abrangendo oito países da região: Argentina, Brasil, México e Venezuela (países federativos), e Chile, Colômbia, Equador e Peru (países unitários). Para cada um dos países estudados, além do levantamento da legislação nacional sobre a questão metropolitana, também foi realizado um estudo de caso para ilustrar a aplicação dos marcos legais. Nesse sentido, foram apresentados os estudos de caso das regiões metropolitanas de Buenos Aires/ARG, Rio de Janeiro/BRA, Guadalajara/MEX, Caracas/VEN, Santiago/CHL, Valle de Aburrá - Medellín/COL, Quito/ECU e Lima/PER. Este estudo comparativo se deu no âmbito de uma pesquisa realizada pela CEPAL em parceria com o IPEA, no ano de 2019, e permite entender as formas atuais de governança e articulação político-administrativa, as novas experiências presentes no subcontinente e a forma como os arranjos institucionais e os desenhos federativos afetam a governança das metrópoles.

Palavras-chave: regiões metropolitanas, governança, gestão, América Latina.

Linha de Investigação: 1 . Cidade e projeto

Tópico: Planejamento, políticas e governança

\section{ABSTRACT}

Covering eight countries in the region: Argentina, Brazil, Mexico and Venezuela (federative countries), Chile, Colombia, Ecuador and Peru (unitary countries), this article aims to understand the main aspects of metropolitan governance in Latin America. For each country studied, a survey of national legislation on the metropolitan issue was carried out, as well as a case report to illustrate the application of legal frameworks. In 


\section{SÃOPAULO15 $17 \cdot$ LISBOA $25 \sim 26$ JUN 2020}

this extent, case reports of the metropolitan regions were presented: Buenos Aires/ARG, Rio de Janeiro/BRA, Guadalajara/MEX, Caracas/VEN, Santiago/CHL, Valle de Aburrá - Medellín/COL, Quito/ECU and Lima/PER. This comparative study happened in the context of a research developed by ECLAC in partnership with IPEA in 2019 and it allows us to understand the current forms of governance and political-administrative articulation, the new experiences present in the subcontinent and the way in which institutional arrangements and federative designs affect the governance of metropolises.

Keywords: metropolitan regions, governance, public administration, Latin America.

Research line: 1 . City and project

Topic: Planning, policies and governance

\section{Introdução}

Estudo recente da instituição Cidades e Governos Locais Unidos, baseado em dados da Organização das Nações e o Caribe, em parceria com o Governo Federal do Brasil, por meio do Instituto de Pesquisa Econômica Aplicada. Para tanto, um grupo de consultores realizou investigações utilizando documentos, leis e dados primários dos mecanismos de governança das áreas metropolitanas da região como fontes de dados $^{1}$.

A partir dos resultados obtidos na pesquisa, esse artigo visa compreender, comparativamente, os principais aspectos da governança metropolitana na América Latina, abrangendo oito países da região, sendo quatro federativos (Argentina, Brasil, México e Venezuela) e quatro unitários (Chile, Colômbia, Equador e Peru). Para cada país, além do levantamento da legislação nacional sobre a questão metropolitana, também foi realizado um estudo de caso para ilustrar a aplicação dos marcos legais. Nesse sentido, foram estudadas as regiões metropolitanas de Buenos Aires (Argentina), Rio de Janeiro (Brasil), Guadalajara (México), Caracas (Venezuela), Santiago (Chile), Valle de Aburrá (Colômbia), Quito (Equador) e Lima (Peru).

Tendo como hipótese que os diferentes regimes políticos (países federativos versus países unitários) resultariam em distintos processos e arranjos metropolitanos - entendendo que países unitários teriam menos entraves na promoção de ações coordenadas entre as instâncias governamentais -, foram investigadas e comparadas as seguintes questões: o marco legal nacional, o processo de formação das regiões metropolitanas, sua governança e estrutura de gestão, além das questões pertinentes ao planejamento e ao financiamento metropolitanos.

O estudo comparativo da governança metropolitana nos permite entender as formas atuais de governança e da articulação político-administrativa, bem como as novas experiências presentes no subcontinente. Isso permitirá maior compreensão. Ciudades y Gobiernos Locales Unidos aponta que existem 503 cidades no mundo com mais de 1 milhão de habitantes (CGLU, 2017: 27-30), denominadas como metrópoles ou cidades metropolitanas. Nessas metrópoles vivem mais de 1,6 bilhão de pessoas (41\% da população urbana mundial), e espera-se que elas recebam, até 2030, mais 600 milhões de habitantes. A América Latina e o Caribe concentram 68 dessas cidades, sendo que 45 delas ficam na América do Sul, totalizando mais de 160

\footnotetext{
${ }^{1}$ Consultores IPEA/CEPAL da Pesquisa Governança Metropolitana na América Latina: Argentina (Silvina Aida Batakis, Patrício Narodowski); Brasil e América Latina (Cid Blanco Junior); Chile (Pablo Fuentes Flores, Rodrigo Caimanque Leverone); Colômbia (Julio Miguel Silva, Manuel Guillermo Bonilla); Equador (Vanessa Rodríguez Egüez); México (Juan Ángel Demerutis Arenas); Perú (Manuel Dammert-Guardia); e Venezuela (Ignacio Cardona, Luis Schloeter, Carlos Urdaneta Troconis).
} 


\section{SÃO PAULO15 17 LISBOA $25 \sim 26$ JUN 2020}

milhões de pessoas, equivalente a $46,6 \%$ do total da população urbana do continente sul-americano e a $71,4 \%$ da população urbana de toda a região.

Dentre os inúmeros estudos sobre as metrópoles latino-americanas, têm destaque aqueles realizados pelo Ipea sobre as RMs brasileiras (Marguti, Costa \& Favarão, 2018), por Filgueiras (2014), sobre as migrações internas em Lima, sobre as metrópoles da Colômbia e do Chile (Holuigue, 2011), do México e Brasil (Rodríguez Vignoli, 2006), de Quito (Martí-Costa, Durán \& Marulanda, 2016) e de Caracas (Lizarraga, 2012). Dada a dimensão do fenômeno metropolitano no território latino-americano, foi realizada uma pesquisa, no segundo semestre de 2019, no âmbito do Programa Executivo de Cooperação de Políticas Públicas para o Desenvolvimento Econômico, Social e Ambiental do Brasil e da América Latina, coordenada pela Comissão Econômica para a América Latina, do atual cenário metropolitano da América Latina e das soluções que estão sendo construídas, que inspiram a experiência dos países da região.

\section{Regiões metropolitanas em oito países latino americanos: os federados e os unitários}

Países federados, federativos, federais ou federações são aqueles formados a partir da união de unidades políticas autônomas ou a partir de unidades territoriais previamente estabelecidas, que resolveram se reunir em torno de uma administração única e soberana, passando a ser regidos por uma Constituição Federal. Com exceção do Brasil, onde os municípios também são considerados entes federados, nos países federativos os governos locais costumam ter apenas autonomia administrativa; sua relação com os demais entes e o grau dessa autonomia diferem em cada país.

Os países unitários são formados por um Estado único, cujo exercício do poder político se dá na figura de uma autoridade central. Qualquer grau de descentralização em relação às unidades subnacionais depende da concordância do poder central. As principais características dos países estudados podem ser observadas na tabela a seguir.

\begin{tabular}{|c|c|c|c|c|}
\hline PAÍS & $\begin{array}{l}\text { POPULAÇÃO } \\
\text { em milhões } \\
(2017)\end{array}$ & $\begin{array}{l}\text { ÁREA } \\
\left(\mathrm{km}^{2}\right)\end{array}$ & $\begin{array}{c}\text { TOTAL DE } \\
\text { MUNICÍPIOS } \\
\text { (governos locais) }\end{array}$ & $\begin{array}{c}\text { COM + DE } 1 \\
\text { MILHÃO DE } \\
\text { HABITANTES }\end{array}$ \\
\hline Argentina* & 44,27 & 2.780 .400 & $\begin{array}{c}376 \text { departamentos } \\
1.793 \text { municípios }\end{array}$ & 3 \\
\hline Brasil $^{*}$ & 209,3 & 8.515 .767 & 5.570 & 17 \\
\hline Chile & 18,05 & 756.950 & $\begin{array}{l}345 \text { municípios/ } \\
346 \text { comunas }\end{array}$ & 1 \\
\hline Colômbia & 48,2 & 1.141 .748 & 1.122 & 4 \\
\hline Equador & 16,62 & 256.370 & 221 cantones & 2 \\
\hline
\end{tabular}




\section{SÃOPAULO15 $17 \cdot$ LISBOA $25 \sim 26$ JUN 2020}

\begin{tabular}{|c|c|c|c|c|}
\hline México* & 124,04 & 1.960 .189 & 2.457 & 13 \\
\hline Peru & 32,17 & 1.285 .220 & 1.869 distritos & 2 \\
\hline Venezuela* & 31,98 & 916.445 & 335 & 5 \\
\hline
\end{tabular}

\subsection{Marco nacional legal e processo de formação}

Um dos principais pontos da pesquisa foi o retrato do processo de reconhecimento, no nível nacional, da formação e da institucionalização das regiões metropolitanas (RMs) em cada país, por meio de suas legislações. Nem todos os países são como a Colômbia que, ainda no final do século XIX, já possuía legislação nacional que indicava as responsabilidades dos departamentos (estados) sobre os processos de planejamento regional e de prestação de serviços, ou como o Brasil, que em sua Constituição Federal de 1937, apresentava a possibilidade de municípios de uma mesma região se organizarem para melhor prestarem serviços públicos comuns.

A América Latina é reconhecida por possuir um dos maiores índices de urbanização do mundo, decorrente do processo de urbanização sem planejamento e controle ocorrido, na maioria dos países, nas décadas de 1960 e 1970. Grande parte dos países teve suas primeiras legislações nacionais sobre a questão metropolitana estabelecidas entre os anos 1970 e 1980, quando a população urbana já era superior a 50\% em vários países da região. Com exceção da Argentina, os demais países pesquisados possuem legislação nacional específica atualizada sobre questões metropolitanas e o tema em suas Constituições.

Além de definir o processo de institucionalização das RMs, bem como o ente ou unidade subnacional responsável pelo ato, algumas legislações nacionais estabelecem conceitos sobre o que é uma região metropolitana e indicam critérios a serem considerados no estabelecimento dessas unidades territoriais.

Para criação das RMs, em sua maioria, é necessária a aprovação de leis específicas ou indicação em planos setoriais (Argentina) para que sua institucionalização ocorra, havendo casos onde essa iniciativa se dá a partir de ação do governo nacional, como no Chile, Peru e Equador (unitários) ou por iniciativa dos estadosmembros (Brasil e México). Merecem destaque dois exemplos que destoam de seus grupos específicos e do grupo geral em si:

- Na Venezuela (federado), quando era possível criar $\mathrm{RMs}^{2}$, o mesmo ocorria por meio de projeto de iniciativa popular ou aprovação de legislação de qualquer um dos níveis de governo, o que permitia, também aos municípios, a possibilidade de se autointitularem uma região metropolitana;

- Na Colômbia (unitário), a institucionalização de RMs é de iniciativa exclusiva dos municípios desde a década de 1980, indicando que há, no país, um nível de descentralização grande sobre o tema; no

\footnotetext{
${ }^{2}$ O texto considera a legislação e os processos antes de 2017, quando era possível a criação de RMs na Venezuela, fato que deixou de existir após a aprovação de Decreto da Assembleia Nacional Constituinte da Venezuela (ANC) que eliminou todos os governos metropolitanos existentes.
} 


\section{SÃOPAULO15 $17 \cdot$ LISBOA $25 \sim 26$ JUN 2020}

presente momento, o processo deve ser acompanhado de consulta popular com aprovação de um quarto da população votante do território a ser declarado metropolitano ${ }^{3}$.

Apesar de serem de regimes distintos, ambos consideram a instância local como responsável pela institucionalização de regiões metropolitanas e contam com processos participativos e de consulta cidadã. Sobre ações de consulta, elas também podem ser encontradas no Equador, onde, uma vez estabelecida a nova RM pelo governo nacional, o processo deverá ser complementado ao final por uma consulta popular, após aprovação pelo Conselho Municipal do Estatuto Autônomo do Distrito Metropolitano, de acordo com o Código Orgánico de Organización Territorial, Autonomías y Descentralización - COOTAD, 2010.

Um ponto importante no processo de criação de regiões metropolitanas dos países estudados, é o fato de que, na Venezuela e no Equador, a formação da unidade territorial metropolitana é procedida da eleição de um prefeito metropolitano por voto popular, bem como seu legislativo. No caso específico equatoriano, essa eleição substitui, automaticamente, os prefeitos dos municípios integrantes da RM, ou seja, ao se formar o distrito metropolitano, os cidadãos dos municípios perdem seus prefeitos e concejales, e participam de um processo de votação para eleição de novos representantes. Sendo assim, o distrito metropolitano se transforma num único município. No caso venezuelano isso não acontecia, o que, por outro lado, causou sobreposições e tensões entre os prefeitos da RM e o novo representante metropolitano eleito. Nos demais países analisados, a criação de uma RM não forma um novo governo, sendo apenas uma forma legal de associação para gerenciamento comum de temas específicos.

No Chile, a criação de uma região metropolitana não cria nova unidade subnacional ou elege prefeito, porém, segundo a Política Nacional de Desenvolvimento Urbano do Ministerio de Vivienda y Urbanismo (MINVU) de 2013, uma vez instituída uma autoridade metropolitana, os governos regionais e comunais que a integram terão atribuições distintas daqueles que não forem metropolitanos e isso será definido caso a caso, de acordo com a legislação.

Sobre os critérios que definem o que são RMs, foram encontrados exemplos, sempre baseados em estudos realizados por instituições federais, indicados na legislação nacional ou estabelecidos na própria Constituição. No México, o estudo "Delimitación de las Zonas Metropolitanas de México", elaborado por equipe multidisciplinar de organismos federais, já teve quatro edições e, desde 2004, tem auxiliado na delimitação de novas áreas metropolitanas.

No caso brasileiro, uma legislação, aprovada em 2015, traz um glossário apresentando os principais conceitos pertinentes à questão metropolitana. A Lei Federal no 13.089/2015 passou para o Instituto Brasileiro de Geografia e Estatística (IBGE) a responsabilidade de fornecer as informações (critérios) necessárias para que um Governo Estadual estabeleça uma nova RM. Entretanto, esses critérios nunca foram explicitados e, até o presente momento, não houve nenhuma publicação específica do IBGE sobre o tema.

No Chile, assim como no Equador, o conceito de região metropolitana considera um número mínimo de habitantes, vinculando os fenômenos de crescimento urbano e conurbação aos dados demográficos, deixando de fora, em alguns casos, territórios com dinâmicas socioeconômicas de caráter metropolitano. No caso chileno, os municípios deverão somar 250 mil habitantes, enquanto no caso equatoriano o número é

\footnotetext{
${ }^{3}$ Fato estabelecido pela Lei n $1.625 / 2013$ - Régimen para las Áreas Metropolitanas. O pesquisador indicou que nenhuma nova RM foi criada desde então devido aos altos custos que uma consulta popular em diversos municípios acarreta, havendo sempre a possibilidade da proposta não ser aprovada.
} 


\section{XII $\quad$ SÃOPAULO $15 \sim 17 \cdot$ LISBOA $25 \sim 26$ JUN 2020}

muito superior, devendo equivaler a $7 \%$ da população total do país, o que, atualmente, representa 1,2 milhão de pessoas.

Com exceção do Brasil, as principais RMs estão estabelecidas nas capitais dos países estudados, o que gera uma série de especificidades ou, até mesmo, limitações. No caso peruano, de acordo com o Sistema Nacional de Centros Poblados (SINCEP), a província de Lima é considerada a única "metrópole nacional" e possui regime especial, formando, com a província de Callao, o território conhecido como Lima Metropolitana, com competências e funções de planejamento e ordenamento, unindo os níveis regional, local e distrital.

No Equador, o Distrito Metropolitano de Quito é a única região metropolitana formada. O caso de Quito também está regulamentado sob regime especial de governo municipal, modo escolhido para gerenciar problemas decorrentes do fenômeno metropolitano. No México, a RM que inclui a capital do país é a única mencionada na Constituição Federal, apesar de o país ter, oficialmente, quase 80 regiões estabelecidas, dispensando a ela tratamento especial.

Na Colômbia, a Ley no 1.625/2013 impede que Bogotá integre uma área metropolitana, ainda que apresente todas as características e problemas de uma e, no Brasil, ainda que seja uma unidade federativa com competências estaduais, a legislação federal veda que Brasília crie e/ou integre RMs, apontando exclusivamente as Regiões Integradas de Desenvolvimento Econômico - RIDEs, como modelo de arranjo interestadual.

As legislações nacionais são responsáveis, em alguns casos, pela definição dos serviços públicos comuns que podem ser compartilhados pelos municípios integrantes nas RMs. Essas são as realidades no Brasil, México, Colômbia, Equador e Peru. Ainda que pareça um processo restritivo, na verdade as alternativas são extensas e garantem que outras opções sejam escolhidas ou incorporadas de outros níveis de governo, como no caso equatoriano. Brasil, Chile e Venezuela tem serviços comuns definidos na lei específica de criação de cada RM. Como na Argentina não há legislação nacional, essa questão se resolve por definição da governança da própria região metropolitana, sendo mais comum os temas referentes ao transporte e uso do solo.

Em suma, apesar de algumas especificidades, no geral, os países possuem legislação vigente atualizada que concede aos governos nacionais ou aos estados-membros a responsabilidade na criação de RMs, com exceção da Colômbia, onde fica a cargo dos municípios. Conceitos e critérios mudam nos diferentes países, mas tendem a garantir que o processo de criação de regiões metropolitanas seja padronizado, evitando assim seu uso meramente por motivos políticos.

Governança metropolitana será aqui entendida como a ação de compartilhar a gestão, as responsabilidades, as decisões e a busca de soluções para os problemas comuns do território metropolitano. Em geral, a governança é composta de diferentes instâncias, sendo as mais comuns: (i) deliberativa, composta em sua maioria pelos representantes governamentais dos diversos níveis; (ii) consultiva, espaço que garante a participação popular; e (iii) executiva, órgão responsável pelo planejamento e execução dos serviços públicos compartilhados metropolitanos.

Com exceção do Equador e da Venezuela, onde as novas prefeituras metropolitanas e suas estruturas correspondem exatamente à governança das RMs, nos demais países estudados todos possuem instâncias deliberativas de gestão formadas pelos prefeitos dos municípios que integram as regiões metropolitanas. $O$ 


\section{SÃO PAULO15 17 LISBOA $25 \sim 26$ JUN 2020}

que é, quem, além dos prefeitos, participa dessa governança, seu grau de autonomia e suas funções. Na Argentina, devido à ausência de uma legislação nacional, cada RM tem seu próprio modelo de governança.

No México e na Colômbia, além dos prefeitos, o governo nacional também possui lugar nas Juntas Metropolitanas, sendo que, no México, o governo estadual tem assento na instância deliberativa, assim como no Brasil e no Chile. O interessante na participação do governo nacional, no caso colombiano, é que ele não possui voto, apenas voz, reafirmando a descentralização de poder para os municípios.

Os representantes do legislativo dos municípios colombianos integrantes da RM também participam da Junta, além da sociedade civil, por meio de uma organização sem fins lucrativos, todos com direito a voto. O governo regional colombiano (departamento), apenas tem espaço nos órgãos de suporte à governança, os Consejos Metropolitanos temáticos e cujo objetivo principal é o planejamento, o que garante lugar para o governo regional, por meio de seu Diretor de Planejamento. No Brasil, a instância deliberativa deverá conter representantes da sociedade civil, com direito a voto, selecionados no âmbito da instância consultiva.

Sobre a participação dos governos regionais/estaduais, no México e no Brasil, países federados, essa participação é ampla, pois os estados-membros são responsáveis técnica e financeiramente pelas instâncias executivas da governança (agências, institutos ou empresas metropolitanas), tendo papel de coordenação na condução dos trabalhos. No caso chileno, país de regime unitário, isso é ainda mais centralizado no governo regional, uma vez que a instância de governança é o próprio Consejo Regional e a instância executiva é apenas um departamento dentro da estrutura administrativa do governo.

Já no Peru, participam do Consejo Metropolitano - órgão normativo e fiscalizador - apenas os representantes dos municípios distritais que integram a RM. Assim como na Colômbia, no exemplo peruano existem órgãos temáticos de assessoramento à governança para a execução dos serviços públicos a seu cargo, sendo os principais a Junta de Planeamiento Metropolitano e a Junta de Cooperación Metropolitana.

Dos cinco países analisados que possuem estrutura de governança deliberativa, apenas a Colômbia não tem uma instância consultiva específica, onde é garantida ampla participação de representantes da sociedade civil.

No Brasil, México e Peru, a sociedade civil participa de conselhos, representando seus próprios municípios, atuando ativamente nos processos de planejamento e gestão das funções comuns de responsabilidade da governança metropolitana. No caso chileno, assim como no conselho deliberativo, é a própria estrutura do governo regional que garante a participação cidadã.

Sobre as instâncias executivas, todos os países têm a sua, porém, os únicos exemplos apresentados nos países estudados, de órgãos efetivos, foram os da Colômbia e do México, no caso as RMs del Valle de Aburrá (Medellín) e de Guadalajara. Nos casos peruano (Gerencia Municipal Metropolitana) e chileno (Administración Área Metropolitana), são as próprias estruturas de governo que respondem pela administração das funções públicas comuns, assim como no Equador e na Venezuela. No Brasil, a legislação estabelece a necessidade de uma instância executora que, no exemplo apresentado (RM do Rio de Janeiro), se encontra em fase de implementação.

De maneira geral, todos os países estudados possuem alguma instância de governança, seja ela deliberativa, consultiva ou executiva, ou mesmo uma estrutura do próprio governo, como são os casos do Chile, Equador, Peru e Venezuela. Em sua grande maioria, os municípios integrantes das RMs e a sociedade civil têm lugar garantido, seja na tomada direta de decisão, seja no processo participativo de escuta das 


\section{SÃOPAULO15 $17 \cdot$ LISBOA $25 \sim 26$ JUN 2020}

demandas da população. Além disso, há casos onde o governo nacional também possui espaço na governança e, em outros exemplos, como no Brasil e México, onde os governos estaduais são responsáveis técnica e financeiramente pelas instituições executivas. Órgãos de assessoramento e agências temáticas dão suporte ao planejamento, à gestão e à execução dos serviços públicos comuns sob responsabilidade metropolitana.

A grande questão é o quanto essas instâncias são efetivas e dão viabilidade à gestão compartilhada dos serviços públicos de interesse comum. Alguns relatos, feitos pelos investigadores, apontaram sobreposições nas competências, disputas políticas e até mesmo ausência de resultados ocorridos, em sua maioria, nos países onde não há uma definição legal clara de papéis ou instâncias específicas para tratar do tema metropolitano. Houve, ainda, menção ao desconhecimento por parte da população das instâncias de participação ou mesmo sobre o fato de que habitam uma RM, cuja gestão é compartida entre vários municípios. Muitos cidadãos não sabem como a governança metropolitana funciona, ou mesmo que ela existe. Apesar disso, a América Latina é referência em gestão metropolitana e o caso colombiano consolidado de Medellín, ainda que não tenha instância participativa, tem sido referenciado em várias publicações sobre o tema, enquanto o caso mexicano de Guadalajara vem sendo apontado como um exemplo em evolução a ser acompanhado.

\subsection{Planejamento}

Planejar e ordenar o território metropolitano são ações de senso comum entre todas as experiências analisadas, inclusive no caso argentino. A necessidade de organização do território contínuo, compartilhado entre os diversos governos locais, é o ponto central da gestão metropolitana. Em diversos casos, a própria legislação nacional traz não somente as competências sobre o planejamento territorial, mas também, instrumentos urbanísticos e requisitos mínimos que deverão ser considerados no plano metropolitano a ser elaborado e aprovado pela governança, como no caso brasileiro.

Ainda que existam RMs nas principais cidades argentinas e que grande parte delas possua planos metropolitanos, muitas vezes realizados por órgãos específicos para o tema, a ausência de uma legislação nacional fragiliza o rebatimento das definições que esses planos propõem no ordenamento do território municipal. Sendo assim, a implementação efetiva desses planos nas RMs argentinas é muito baixa.

Já nos demais países, cada um trata do ordenamento territorial no nível metropolitano com um nome diferente. Exatamente por tratarem do uso e da ocupação do solo, é que muitas vezes começam os problemas na gestão metropolitana, especialmente na relação entre os diferentes níveis de governo.

Em países como Brasil, México, Argentina e Colômbia, o uso do solo é de competência municipal e todos possuem autonomia para isso, de modo que uma definição no nível metropolitano, que não possui caráter hierárquico superior, mesmo havendo legislação nacional tratando do tema, causa desconforto nos prefeitos, que sentem o fato como perda de poder político. Isso acontece porque a legislação nacional indica que o planejamento local deve se adequar ao metropolitano ou regional, tirando parte da autonomia municipal, quando, na verdade, seu principal objetivo é incentivar a cooperação interfederativa na busca por soluções dos problemas comuns.

Destaque importante no caso brasileiro é o fato de que boa parte dos instrumentos urbanísticos previstos no Estatuto da Metrópole são versões metropolitanas do Estatuto da Cidade (Lei Federal no 10.257/2001), marco legal que regulamenta os artigos referentes à política urbana da Constituição do país. Esses instrumentos urbanísticos são um conjunto de ações e dispositivos legalmente possibilitados ao poder 


\section{SÃOPAULO15 $17 \cdot$ LISBOA $25 \sim 26$ JUN 2020}

público para intervir nos processos urbanos, por meio da regulamentação, controle ou direcionamento destes processos, podendo ser utilizados, pelo planejador municipal, na obtenção de resultados positivos na gestão democrática e participativa do território municipal. Dos dez instrumentos estabelecidos, apenas quatro são totalmente novos e inovadores, pois trazem para a escala metropolitana instrumentos antes existentes apenas na escala municipal.

Em países unitários como Chile, Peru e Equador, parte do ordenamento territorial é definido nacionalmente ou regionalmente, fazendo com que haja uma sobreposição de papéis e indefinições do ponto de vista metropolitano, que acaba se estendendo, muitas vezes, para o nível local.

Para além do planejamento e do ordenamento do uso do solo, são muitos os casos onde são realizados planos setoriais metropolitanos, em sua grande maioria, de mobilidade urbana. Muitas vezes, devido às divergências na questão do uso do solo e da necessidade urgente de solucionar o transporte público nas grandes metrópoles, os planos de mobilidade acabam sendo realizados antes mesmo dos planos metropolitanos, uma vez que são um dos principais serviços públicos compartilhados na gestão metropolitana.

Do ponto de vista do planejamento, todos os países apresentam instrumentos que podem ser usados para planejar e ordenar o território metropolitano. A interlocução desses planos com o planejamento de responsabilidade das demais esferas de governo, seja nacional, regional ou local, acontece de maneira distinta nos países, mas no geral, apresenta problemas, com sobreposições ou sentimento de perda de poder político.

\subsection{Financiamento}

Para finalizar, o último ponto analisado na pesquisa foi o modelo de financiamento da gestão e do planejamento metropolitanos. Tema delicado, pois é quando as desigualdades entre os municípios das RMs se tornam mais evidentes, em especial na relação cidade-polo com as cidades-dormitório das periferias metropolitanas, que possuem baixa arrecadação e capacidade técnica.

Os regimes políticos pouco influem na proposta de financiamento, porém, os modelos de governança influem muito nesse sentido. No Equador e na Venezuela, onde há a constituição de um novo governo, as receitas municipais acabam se tornando a própria receita metropolitana, ainda que no caso venezuelano os municípios continuem existindo. Os recursos específicos para a RM na Venezuela eram provenientes da participação em tributos e tarifas de serviços prestados em nível metropolitano. Recursos regionais e nacionais também são considerados como fontes de financiamento, nos dois casos, para a execução de obras e serviços.

Mesmo sem formar uma nova unidade subnacional, o mesmo acontece no Peru, já que há sobreposição entre os níveis de governo regional, provincial e distrital, de modo que as fontes de financiamento acabam sendo os recursos dos diferentes governos, em especial os de Lima Metropolitana, que acabam compondo, praticamente, todo o orçamento da RM. Não há, nesse caso, fontes de recursos nacionais.

Ter como fonte de recursos as receitas dos próprios níveis de governo que integram a RM é também o caso da Argentina e do Brasil, onde também não há fontes de recursos específicas vindas dos governos nacionais, variando caso a caso. Na Argentina, cada arranjo metropolitano tem proposta própria de compartilhamento de recursos, entretanto, no geral, eles acabam sendo oriundos, principalmente, das cidades-sede da RM. No caso brasileiro, os valores são provenientes do sistema integrado de divisão dos custos da governança e dos 


\section{SÃO PAULO15 17 LISBOA $25 \sim 26$ JUN 2020

serviços que venham a ser realizados, sempre considerando o acordo de participação de cada ente federado (estado e municípios) destinado ao financiamento, estabelecidos na lei de formação da RM.

$\mathrm{Na}$ Colômbia, os recursos são unicamente dos municípios e vem da sobretaxa de $0,2 \%$ na avaliação cadastral das propriedades localizadas na jurisdição de cada região metropolitana, além do percentual das contribuições de participação destinadas ao financiamento das funções das RMs estabelecido pelos acordos municipais. Existem, ainda, contribuições, taxas, direitos, tarifas e multas pelo uso e aproveitamento dos recursos naturais renováveis, bem como taxas, tarifas, direitos, multas ou autorizações recebidas no exercício da autoridade de transporte ou de outros temas que tenham sido concedidos ou reconhecidos como de interesse metropolitano.

Já no Chile, os recursos são do governo nacional e do regional, por meio do Fondo Nacional de Desarrollo Regional e outros fundos regionais, sem que os municípios tenham responsabilidade direta no financiamento da gestão metropolitana, num processo muito centralizado.

Por fim, no México, ainda que os governos estaduais sejam responsáveis técnica e financeiramente pela gestão metropolitana, há acordos para compartilhamento dos gastos com os municípios, que assim como no exemplo brasileiro, geralmente não participam financeiramente do rateio das despesas. O principal diferencial entre os casos mexicano e o brasileiro é a existência de um fundo nacional, o Fondo Metropolitano, cujos recursos financiam boa parte dos grandes investimentos nas RMs do país. $\mathrm{O}$ acesso aos recursos do Fondo é tido por alguns, segundo o investigador mexicano, como um estímulo para a formação de regiões metropolitanas, pois muitos Estados criam RMs apenas para poder participar dos processos de seleção dos recursos, ainda que os territórios não possuam dinâmica ou características efetivamente metropolitanas.

Processo similar é descrito na experiência brasileira, onde, devido à utilização de regiões metropolitanas como grupo de priorização de programas e projetos federais, em especial vinculados aos temas urbanos, muitos Estados criaram RMs, sem que esses territórios fossem, efetivamente, metrópoles.

Os financiamentos da gestão e do planejamento metropolitanos se dá de modo variado nos países focos da pesquisa, porém, em todos os casos, têm por base recursos públicos, de diferentes níveis de governo. Há casos onde os recursos são oriundos, principalmente, dos governos locais (Argentina, Colômbia, Equador e Venezuela), podendo receber, também, de outras fontes; há os que os recursos são, principalmente, dos governos estaduais, com pouca participação dos municípios (Brasil e México); ou dos governos nacional e regional, sem participação dos municípios (Chile) na composição dos fundos; e há, também, casos onde a sobreposição de competências acaba deixando boa parte da conta para a cidade-sede (Peru). Os casos mexicano e chileno são os únicos que apresentaram fundos nacionais exclusivos para o tema metropolitano.

\section{Considerações Finais}

Os oitos países analisados na pesquisa - Argentina, Brasil, Chile, Colômbia, Equador, México, Peru e Venezuela - possuem mais semelhanças do que diferenças no tema metropolitano, especialmente se levados em conta seus diferentes regimes políticos e desdobramentos locais; as diferenças e, em especial, as semelhanças, independem dos regimes políticos adotados por cada país e acabam sendo consequência dos processos de urbanização e metropolização ocorridos na região.

Federativos ou unitários, todos os países apresentam, por meio de suas legislações ou iniciativas, propostas para tratar da questão metropolitana, apesar das dificuldades encontradas e disputas políticas que ficam 


\section{SÃOPAULO15 $17 \cdot$ LISBOA $25 \sim 26$ JUN 2020}

evidentes em vários momentos. Avaliando marcos legais, processos de formação, critérios e conceitos, propostas de governanças, planejamento e gestão, podemos, assim, dividi-los em quatro grupos:

- Sem marco legal nacional, mas com fenômeno metropolitano consolidado: caso da Argentina, onde apesar da ausência de legislação nacional, as principais cidades do país compõem RMs e têm organizados serviços ou processos de gestão do território, a partir da lógica metropolitana;

- Com marco legal nacional estabelecido, implementação em fase de consolidação: são os casos do Brasil, Colômbia e México, onde as competências dos diferentes níveis de governo são definidas na legislação nacional, bem como vários processos da gestão e do planejamento metropolitanos;

- Com marco legal nacional pensado para efetivar o já existente: são os casos do Peru e do Chile, cuja legislação trata, quase que exclusivamente, dos processos metropolitanos das capitais, em alguns casos, criando regimes especiais para adequar a legislação aos processos metropolitanos já existentes, como um redesenho institucional de territórios específicos; e

- Com formação de uma nova institucionalidade: são os casos do Equador e da Venezuela que, graças a processos eleitorais, elegem prefeitos metropolitanos, formando uma nova unidade territorial no caso equatoriano, e um novo ator político, no caso venezuelano.

Apesar do panorama aqui apresentado, o tema metropolitano vem ganhando cada vez mais destaque nas agendas políticas dos países latino-americanos, fato comprovado pela recente aprovação dos marcos legais estudados. Seguem, ainda, o desafio da efetivação do que está previsto nessas legislações, bem como o efetivo compartilhamento das responsabilidades no planejamento e no financiamento dos serviços públicos comuns compartilhados, para equacionar os problemas dos territórios metropolitanos.

\section{Bibliografia}

CIUDADES Y GOBIERNOS LOCALES UNIDOS, CGLU. (2017). Cuarto Informe Mundial sobre la Descentralización y la Democracia Local: co-creando el futuro urbano - la agenda de las metrópolis, las ciudades y los territorios - GOLD IV. Barcelona: CGLU.

MARGUTI, B.O; COSTA, M. A.; FAVARÃO, C. B. (Orgs.). (2018). Brasil metropolitano em foco: desafios à implementação do Estatuto da Metrópole. Brasília: Ipea.

\section{Fontes eletrônicas}

FILGUEIRAS, B. S. C. (2014). As migrações internas e seu protagonismo contemporâneo nos imaginários urbanos da metrópole de Lima, Peru. Cadernos Metrópole, 16(31), 171-196. https://doi.org/10.1590/22369996.2014-3108

HOLUIGUE, C. (2011). Institucionalidad y transporte público urbano: Santiago de Chile y Medellín, Colombia. Innovación ambiental de servicios urbanos y de infraestructura: Hacia una economía baja en carbono. Santiago de Chile: CEPAL, https://repositorio.cepal.org/bitstream/handle/11362/3950/1/S1100536 es.pdf

LIZARRAGA, C. (2012). Expansión metropolitana y movilidad: el caso de Caracas. EURE (Santiago), 38(113), 99-125. https://doi.org/10.4067/S0250-71612012000100005 


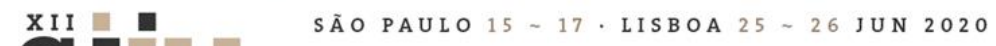

MARTÍ-COSTA, M.; DURÁN, G. MARULANDA, A. (2016). Entre la movilidad social y el desplazamiento: Una aproximación cuantitativa a la gentrificación en Quito. Revista INVI, 31(88), 131-160. https://doi.org/10.4067/S0718-83582016000300005

RODRÍGUEZ VIGNOLI, J. (2006). Segregación residencial socioeconómica (SRS) y sus relaciones con la migración intrametropolitana en cuatro aglomerados urbanos de América Latina. Los casos de Ciudad de México, Santiago de Chile, São Paulo y Rio de Janeiro en los decenios de 1980 y 1990. II Congreso de la Asociación Latinoamericana de Población, Guadalajara, 3-5 septiembre. http://www.alapop.org/Congreso06/DOCSFINAIS PDF/ALAP 2006 mt01s1 4 01.pdf 